\title{
Low expression of AIM2 combined with high expression of p-STAT3 is associated with poor prognosis in hypopharyngeal squamous cell carcinoma
}

\author{
ZHEN LI ${ }^{1,2}$, XINLI SHI $^{2,3}, \mathrm{HUI} \mathrm{LI}^{4}$, WEIYI WANG ${ }^{2}$ and XIAOMING LI ${ }^{1,2}$ \\ ${ }^{1}$ Department of Otolaryngology, Chinese People's Liberation Army General Hospital, Beijing 100853; \\ ${ }^{2}$ Department of Otolaryngology Head and Neck Surgery, Bethune International Peace Hospital, Shijiazhuang, Hebei 050082; \\ ${ }^{3}$ Department of Pathobiology and Immunology, Hebei University of Chinese Medicine, Shijiazhuang, Hebei 050200; \\ ${ }^{4}$ Department of Pathology, Bethune International Peace Hospital, Shijiazhuang, Hebei 050082, P.R. China
}

Received July 30, 2018; Accepted February 11, 2019

DOI: 10.3892/or.2019.7029

\begin{abstract}
Studies indicate that the AIM2 inflammasome plays an important role in tumor occurrence and development. The present study examined the prognostic significance of AIM2 expression and the correlation between AIM2 expression and p-STAT3 expression in hypopharyngeal squamous cell carcinoma (HSCC), which remain unknown. AIM2 and p-STAT3 were detected using immunohistochemistry (IHC) in 111 paraffin-embedded tissue samples from primary HSCC sites and 20 samples from matched adjacent non-malignant sites. Western blotting was utilized to investigate AIM2, p-STAT3 and total STAT3 in 5 pairs of fresh tissue samples. Western blotting indicated that AIM2 expression was significantly lower $(\mathrm{P}<0.05)$, but that $\mathrm{p}$-STAT3 levels and the p-STAT3/STAT3 ratio were higher $(\mathrm{P}<0.01)$ in HSCC tissues than in adjacent normal hypopharyngeal tissues. IHC analysis of the 111 HSCC samples revealed low AIM2 and high p-STAT3 expression in 48 (43.2\%) and $58(52.3 \%)$ samples, respectively. High AIM2 expression and low p-STAT3 expression were detected in $13(75 \%)$ and $18(90 \%)$ adjacent normal hypopharyngeal tissue samples, respectively. In the HSCC samples, low AIM2 expression was closely related to lymph node metastasis and intravascular tumor thrombus $(\mathrm{P}<0.05)$. Kaplan-Meier survival curves revealed that low AIM2 levels were strongly associated with poor survival for HSCC patients $(\mathrm{P}<0.0001)$. Additionally, Cox proportional hazards regression models indicated that low AIM2 expression significantly
\end{abstract}

Correspondence to: Professor Xiaoming Li, Department of Otolaryngology, Chinese People's Liberation Army General Hospital, 28 Fuxing Road, Beijing 100853, P.R. China

E-mail:xmlmo@126.com

Key words: absent in melanoma 2, phosphorylated signal transducers and activators of transcription 3 , hypopharyngeal squamous cell carcinoma, prognosis, immunohistochemistry predicted poor prognosis for HSCC patients $(\mathrm{P}<0.0001)$, and multivariate analysis revealed that AIM2 expression could be an independent prognostic factor for HSCC patients $(\mathrm{P}<0.0001)$. Furthermore, AIM2 expression was negatively correlated with p-STAT3 expression in the HSCC tissue samples, and combined analysis revealed that patients with low AIM2 and high p-STAT3 levels had the worst survival rate. Moreover, receiver operating characteristic (ROC) curve analysis confirmed that AIM2 was predictive of specific survival in all HSCC patients [area under the curve (AUC) $=0.7160$ ]. In conclusion, our data suggested that for HSCC patients, AIM2 and p-STAT3 expression detected via IHC could serve as a biomarker to predict tumor progression and as an independent prognostic factor.

\section{Introduction}

Head and neck squamous cell carcinoma (HNSCC) is the sixth most common malignant tumor worldwide, accounting for $7 \%$ of all malignant tumors (1). Hypopharyngeal squamous cell carcinoma (HSCC) is one of the subtypes of HNSCC, accounting for $2-6 \%$ of HNSCC cases (2-4). The most common pathological site of HSCC is the pyriform sinus, followed by the postcricoid region and the posterior pharyngeal wall. Since the primary tumor location of HSCC is rather hidden, most of the cancer cells grow in an infiltrative manner and can easily invade into the submucosal layer; thus, early symptoms in HSCC patients are not typical. The majority of HSCC patients are diagnosed at an advanced stage, after cervical lymph node metastasis, which makes HSCC the malignant tumor with the worst treatment outcome among HNSCC subtypes. Although the treatment efficacy of surgery and chemoradiotherapy for HSCC has improved in recent years, $50 \%$ of patients still experience relapse 1 year later $(3,5)$; additionally, the 5-year survival rate of patients has not significantly improved $(2,6)$. To date, no specific and/or sensitive biomarker can accurately predict HSCC prognosis after surgery or chemoradiotherapy. Therefore, it is necessary to develop new biomarkers with better specificity and sensitivity for the clinical assessment of HSCC prognosis. 
Evidence shows that chronic inflammation is closely associated with many cancers, and 'abnormal inflammation in cancer' or 'cancer-related inflammation' has recently been identified as a marker of 'category VII cancer'. As a key factor in inflammatory reactions, the inflammasome is a multiprotein complex. Its activation can facilitate the maturity and secretion of the proinflammatory cytokines IL-1 $\beta$ and IL-18 (7). Recent studies have shown that AIM2 is also a natural immunosensor in the cytoplasm and that it can identify double-strand DNA (dsDNA) derived from microorganisms and the host. The multiprotein complex assembled by AIM2 after its binding with dsDNA is called the AIM2 inflammasome $(8,9)$. The AIM2 inflammasome is one of the important inflammasomes in the body. To date, AIM2 has been found to play an important role in the development and progression of colon cancer, nasopharyngeal carcinoma, melanoma, and prostate cancer. Decreased expression of AIM2 and microsatellite instability of frequent frameshift mutations have been observed in the tumor tissues of patients with colorectal cancer (10-13). In colorectal cancer (10) and nasopharyngeal carcinoma (14), patients with decreased levels of AIM2 expression had a poorer prognosis than patients with elevated levels of AIM2 expression. AIM2 expression was also found to be decreased in prostate cancer (15). In contrast, its expression levels were increased in nasopharyngeal carcinoma $(15,16)$, lung adenocarcinoma (17), and oral squamous cell carcinoma (18). However, the relationship between AIM2 expression and prognosis in HSCC is unclear.

STAT3 is a protein encoded by a proto-oncogene, and p-STAT3 is the activated state of STAT3. p-STAT3 promotes the occurrence and development of tumors through various aspects and pathways, and it participates in many mechanisms that interact with one another. STAT3 is constitutively activated in many human primary malignant tumors, such as liver (19), breast (20), lung (21) and prostate cancer (22), HNSCC (23), pancreatic (24) and kidney cancer (25), leucocythemia (26), rectal cancer (27), lymphoma (28), melanoma (29) and neurospongioma (30). High expression of p-STAT3 has been detected in almost all human malignant tumors, particularly malignant solid tumors. Activated STAT3 has been detected in $>50 \%$ of liver cancer, lung cancer and breast cancer cells and in $>95 \%$ of HNSCC cells (31). p-STAT3 is also an important indicator of prognosis in HNSCC patients (32) and is considered to be an ideal therapeutic target $(33,34)$.

Although several studies have shown that p-STAT3 is a key factor in the transformation of chronic inflammatory diseases to malignant tumors and that p-STAT3 expression is predictive of prognosis in HSCC patients (35), the association of both AIM2 and p-STAT3 expression with clinicopathological characteristics is unknown. Therefore, the present study was performed to investigate the clinical and prognostic influence of the expression of AIM2 and p-STAT3 in HSCC patients. Immunohistochemistry (IHC) and western blotting were performed to detect the expression levels of AIM2 and p-STAT3 in 111 HSCC specimens and normal hypopharyngeal tissues as controls. We found that low expression of AIM2 and high expression of p-STAT3 were associated with poor prognosis in HSCC patients.

\section{Materials and methods}

Patients and tissue specimens. Paraffin-embedded tissue samples from 111 patients with HSCC were obtained from dissected tissues in the archives of the Department of Otolaryngology-Head and Neck Surgery, Bethune International Peace Hospital (Shijiazhuang, China), between 2003 and 2015. Tissue samples from corresponding adjacent normal hypopharyngeal tissues from 20 cases were used as a control. The inclusion criteria of the patients were as follows: i) A definite pathological diagnosis of HSCC; ii) no anticancer treatment (including chemoradiotherapy or biotreatment) before hypopharyngeal resection; iii) absence of common diseases such as diabetes, hypertension, coronary heart disease (CHD), and no history of long-term drug use; iv) availability of formalin-fixed, paraffin-embedded tissues after the excision of lesion with no $<250$ tumor cells in the fixed tissues; and v) availability of complete clinicopathological and follow-up data. The 111 patients with HSCC were aged from 37 to 82 years, with a mean age of 61 years, and the average follow-up duration was 45.8 months (range, 4-170 months). The clinicopathological characteristics of the HSCC patients are summarized in Table I. The clinical stage of tumors was evaluated on the basis of the pharyngeal cancer staging system of the American Joint Committee on Cancer (AJCC) in 2016. The surgical procedures for HSCC involved the resection of HSCC with or without preservation of laryngeal function. Both procedures were accompanied by routine neck lymph node dissection with ipsilateral lesion or bilateral neck lymph node dissection beyond the midline of the lesion. Survival time was defined as the interval from surgery to death or the interval from surgery to the last follow-up date for surviving patients.

The study was approved by the Medical Ethics Institute of Bethune International Peace Hospital. All samples were anonymous. Moreover, fresh tissue specimens from $5 \mathrm{HSCC}$ and corresponding adjacent normal hypopharyngeal tissues were collected for western blotting at our institute in 2016. Corresponding adjacent normal hypopharyngeal tissue with $1.5 \mathrm{~cm}$ of cancer margin was selected during surgery. (Postoperative pathology confirmed that this tissue was non-cancerous).

Western blot analysis. Total protein was isolated using RIPA lysis buffer (Beijing Solarbio Science \& Technology Co., Ltd., Beijing, China) from 5 fresh biopsy specimens of HSCC tissues and adjacent normal hypopharyngeal tissues. Protein concentrations were determined by the BCA method. Equal amounts of tissue lysates $(20 \mu \mathrm{g})$ were resolved by $10 \%$ SDS-polyacrylamide gel electrophoresis (PAGE) and electrotransferred onto a polyvinylidene fluoride (PVDF) membrane (EMD Millipore, Billerica, MA, USA). After blocking with TBS plus $5 \%$ non-fat milk for $2 \mathrm{~h}$ at room temperature, the membranes were incubated with primary anti-human AIM2 (dilution 1:1,000; cat. no. ab93015; Abcam, Cambrige, MA, USA), p-STAT3 (Tyr705; dilution 1:1,000; cat. no. Ab76315; Abcam), STAT3 (dilution 1:2,000; cat. no. CST4904T; Cell Signaling Technology, Shanghai, China) and actin (dilution 1:5,000; cat. no. BE0021; Shenzhen Bioeasy Biotechnology Co., Ltd., Shenzhen, China). After washing for 
Table I. Association of AIM2 expression with the clinicopathological characteristics of patients with HSCC.

\begin{tabular}{|c|c|c|c|c|c|}
\hline \multirow[b]{2}{*}{ Variable } & \multirow[b]{2}{*}{ All patients } & \multicolumn{4}{|c|}{ AIM2 protein } \\
\hline & & $\begin{array}{c}\text { Low } \\
\text { expression }\end{array}$ & $\begin{array}{c}\text { High } \\
\text { expression }\end{array}$ & $\chi^{2}$ & P-value ${ }^{a}$ \\
\hline Age at surgery & & & & 0.086 & 0.7698 \\
\hline$<60$ & 48 & 20 & 28 & & \\
\hline$\geq 60$ & 63 & 28 & 35 & & \\
\hline Sex & & & & Fisher's exact test & 0.0684 \\
\hline Male & 93 & 44 & 49 & & \\
\hline Female & 18 & 4 & 14 & & \\
\hline Side & & & & 0.721 & 0.3957 \\
\hline Left & 55 & 26 & 29 & & \\
\hline Right & 56 & 22 & 34 & & \\
\hline Site of primary tumor & & & & 4.871 & 0.0875 \\
\hline Postcricoid region & 6 & 0 & 6 & & \\
\hline Pyriform sinus & 84 & 38 & 46 & & \\
\hline Posterior pharyngeal wall & 21 & 10 & 11 & & \\
\hline Histological grade & & & & 2.137 & 0.3435 \\
\hline I (Well) & 18 & 5 & 13 & & \\
\hline II (Moderate) & 68 & 31 & 37 & & \\
\hline III (Poor) & 25 & 12 & 13 & & \\
\hline Tumor size $\left(\mathrm{cm}^{2}\right)$ & & & & Fisher's exact test & 0.8315 \\
\hline$<6$ & 29 & 12 & 17 & & \\
\hline$\geq 6$ & 82 & 36 & 46 & & \\
\hline Growth pattern & & & & Fisher's exact test & 0.4134 \\
\hline Ulcerative & 46 & 23 & 23 & & \\
\hline Protruding & 58 & 23 & 35 & & \\
\hline Mixed & 7 & 2 & 5 & & \\
\hline Depth of invasion & & & & 0.2714 & 0.8731 \\
\hline Submucosa & 47 & 19 & 28 & & \\
\hline Muscular layer & 46 & 21 & 25 & & \\
\hline External laryngeal tissue & 18 & 8 & 10 & & \\
\hline Tumor stage & & & & & \\
\hline T status & & & & Fisher's exact test & 0.9020 \\
\hline $\mathrm{T} 1$ & 2 & 1 & 1 & & \\
\hline $\mathrm{T} 2$ & 15 & 6 & 9 & & \\
\hline $\mathrm{T} 3$ & 43 & 17 & 26 & & \\
\hline $\mathrm{T} 4$ & 51 & 24 & 27 & & \\
\hline $\mathrm{N}$ status & & & & 4.483 & 0.0342 \\
\hline No & 35 & 10 & 25 & & \\
\hline $\mathrm{N} 1 / \mathrm{N} 2 / \mathrm{N} 3$ & 76 & 38 & 38 & & \\
\hline Clinical stage & & & & Fisher's exact test & 0.0934 \\
\hline Stage I & 2 & 1 & 1 & & \\
\hline Stage II & 8 & 4 & 4 & & \\
\hline Stage III & 17 & 3 & 14 & & \\
\hline Stage IV & 84 & 40 & 44 & & \\
\hline Intravascular tumor thrombus & & & & 14.620 & 0.0001 \\
\hline Yes & 51 & 32 & 19 & & \\
\hline No & 60 & 16 & 44 & & \\
\hline Nerve invasion & & & & 0.510 & 0.4750 \\
\hline Yes & 22 & 11 & 11 & & \\
\hline No & 89 & 37 & 52 & & \\
\hline
\end{tabular}


Table I. Continued.

\begin{tabular}{|c|c|c|c|c|c|}
\hline \multirow[b]{2}{*}{ Variable } & \multirow[b]{2}{*}{ All patients } & \multicolumn{4}{|c|}{ AIM2 protein } \\
\hline & & $\begin{array}{c}\text { Low } \\
\text { expression }\end{array}$ & $\begin{array}{c}\text { High } \\
\text { expression }\end{array}$ & $\chi^{2}$ & P-value ${ }^{a}$ \\
\hline Lymphatic metastasis & & & & 4.483 & 0.0342 \\
\hline Yes & 76 & 38 & 38 & & \\
\hline No & 35 & 10 & 25 & & \\
\hline Radiotherapy after surgery & & & & 1.627 & 0.2021 \\
\hline Yes & 83 & 33 & 50 & & \\
\hline No & 28 & 15 & 13 & & \\
\hline Complications after surgery & & & & 0.8811 & 0.3479 \\
\hline Yes & 21 & 11 & 10 & & \\
\hline No & 90 & 37 & 53 & & \\
\hline p-STAT3 & & & & Fisher's exact test & $<0.0001$ \\
\hline Low expression & 53 & 9 & 44 & & \\
\hline High expression & 58 & 39 & 19 & & \\
\hline
\end{tabular}

${ }^{a}$ Chi-square test. HSCC, hypopharyngeal squamous cell carcinoma.

three times with TBST, the membranes were incubated with a horseradish peroxidase-conjugated secondary antibodies (goat anti-rabbit, dilution 1:10,000; cat. no. BE0101; goat anti-mouse, dilution 1:10,000; cat. no. BE0102; both were from Shenzhen Bioeasy Biotechnology Co., Ltd.) for $1 \mathrm{~h}$ at room temperature. The immunoreactive signals were detected with an enhanced chemiluminescence kit (EMD Millipore). All procedures were conducted according to the manufacturer's instructions. Images were captured using a UVP Gel imaging system (Junyi Corp., Beijing, China). Strips were evaluated via gray value analysis using ImageJ software (National Institutes of Health, Bethesda, MD, USA).

IHC. The expression of the AIM2 protein was detected by immunohistochemistry (IHC). Five-micrometer-thick tissue sections were deparaffinized and rehydrated conventionally with dimethylbenzene and graded alcohol, and then rinsed with phosphate-buffered saline (PBS) for $5 \mathrm{~min}$. The tissue sections were incubated with $3 \% \mathrm{H}_{2} \mathrm{O}_{2}$ for 30 min to block the activity of endogenous peroxidases. The sections were washed with buffer for 5 min to deactivate $\mathrm{H}_{2} \mathrm{O}_{2}$. The tissues were incubated in diluted normal serum at room temperature for $20 \mathrm{~min}$; the source of serum was the same as that of the secondary antibody. The blocking liquid was decanted, and no washing was performed. The tissue sections were incubated with a 1:100 dilution of anti-AIM2 polyclonal antibody and a 1:50 dilution of anti-p-STAT3 polyclonal antibody for $30 \mathrm{~min}$ and then rinsed with PBS for $5 \mathrm{~min}$. The slides were incubated with 1:200 diluted biotinylated goat-anti-rabbit solution (Vector Laboratories, Inc., San Francisco, CA, USA; cat. no. PK-4001) for $30 \mathrm{~min}$, and then washed with PBS for $5 \mathrm{~min}$. The tissue sections were incubated in Vectastain ABC reagent for $30 \mathrm{~min}$ and washed with PBS for $5 \mathrm{~min}$. The slides were incubated in peroxidase substrate until the desired staining intensity was reached. Finally, the sections were washed with tap water, counterstained with hematoxylin, differentiated, dehydrated, hyalinized and sealed.

Measurement of AIM2 and p-STAT3 expression by IHC assay. Five random fields were selected from each slide for scoring, and the mean score for each slide was used for the final analysis. Positive staining was assessed using a four-point scoring system: 0 ( $0-10 \%$ positive cells), 1 (11-35\% positive cells), 2 (36-70\% positive cells) and 3 ( $>70 \%$ positive cells). To ensure the greatest objectivity, the intensity of positive staining was also evaluated using a three-point scoring system: 0 (negative staining), 1 (weak or light-yellow staining), and 2 (strong or yellow-brown staining). The expression index of AIM2 and p-STAT3 was calculated as follows: Expression index = (intensity score) x (positive score). To obtain more accurate scores, 2 independent senior observers (Jie An and Hui Li) who were blinded to the available clinicopathological data and outcomes of HSCC patients assessed all IHC samples (including tumor tissues and normal control tissues). Discrepant results of the same tissue sections were re-evaluated by both observes to obtain a consistent result. The cut-off scores for high and low levels of AIM2 and p-STAT3 expression were obtained based on heterogeneity measurements, and the survival rate of HSCC patients was analyzed by a log-rank test. The optimal cut-off for this evaluation system was determined as follows: high expression of AIM2 and p-STAT3 were indicated by an expression index of $>1$, and low expression of AIM2 and p-STAT3 were indicated by an expression index of $\leq 1$.

Selection of cut-off scores. Data were imported from our clinical research datasets according to the method described by a previous study (36). The optimal cut-off was ascertained, and analysis charts were generated by $\mathrm{R}$ statistical software 
A
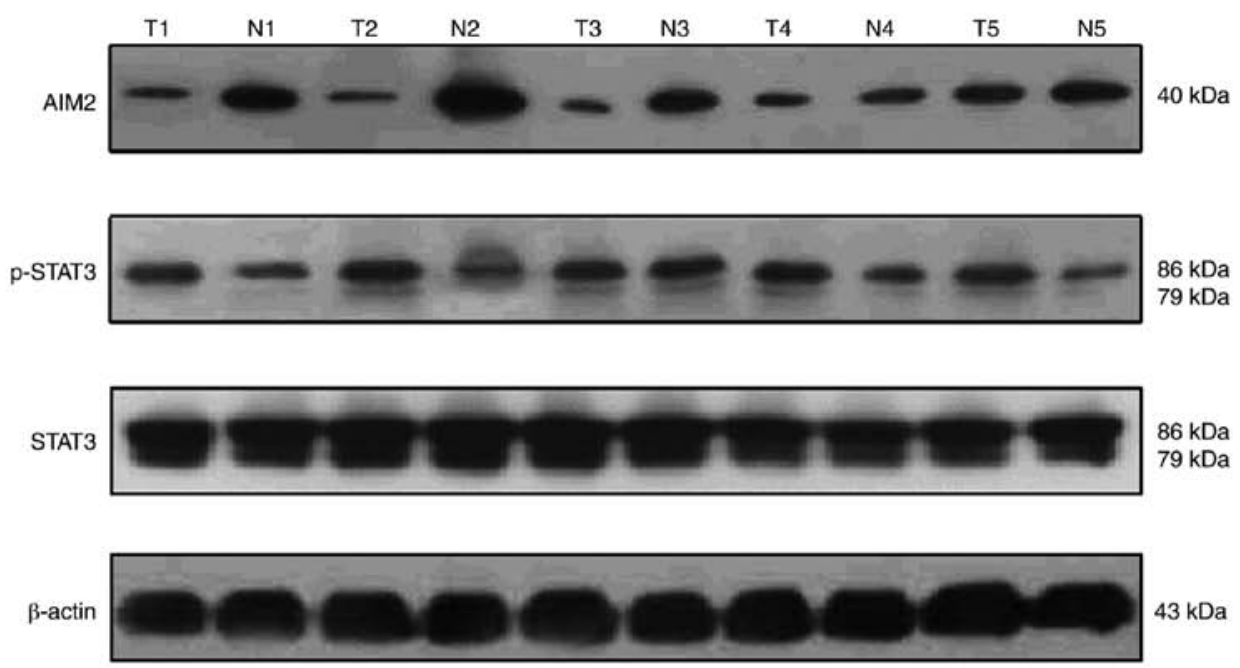

B

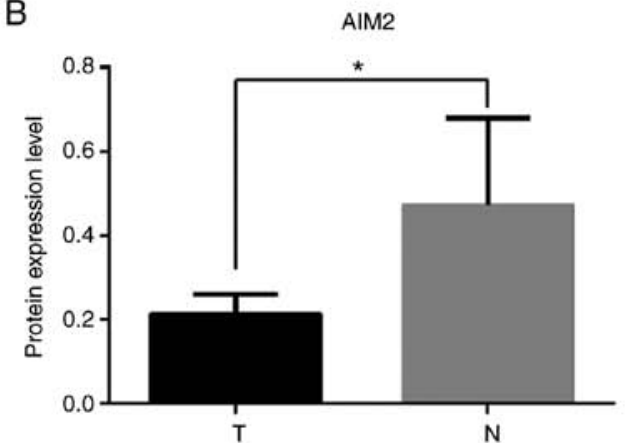

C

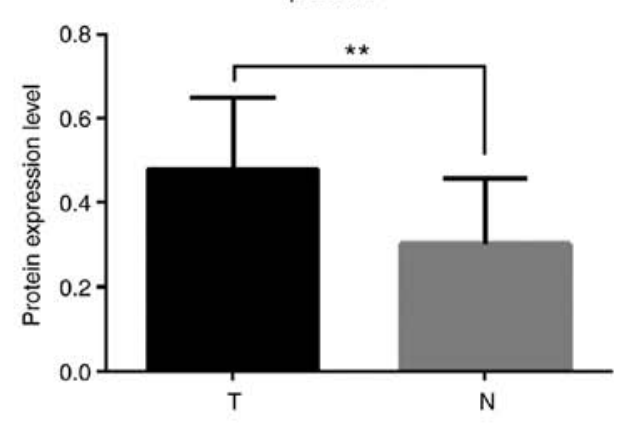

D p-STAT3/STAT3

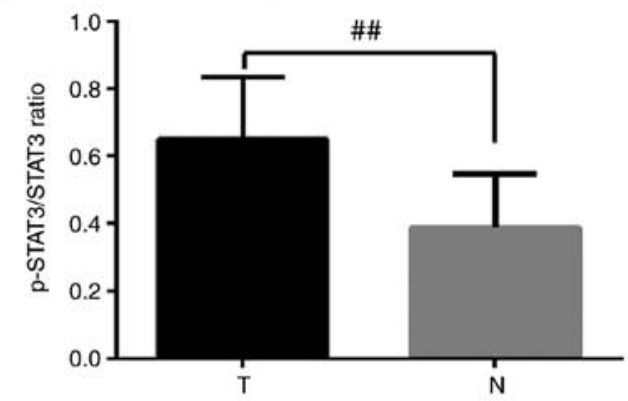

Figure 1. Western blot analysis of AIM2, p-STAT3 and STAT3 in HSCC tissues (T) and adjacent normal hypopharyngeal tissues (N). (A) AIM2, p-STAT3 and STAT3 expression was analyzed in HSCC tissues (T) and adjacent normal hypopharyngeal tissues (N) by western blotting. (B and C) Expression of AIM2 and p-STAT3 proteins in HSCC tissues (T) and adjacent hypopharyngeal tissues (N) was analyzed using paired t-tests. (D) The p-STAT3/STAT3 ratio in HSCC tissues (T) and adjacent hypopharyngeal tissues $(\mathrm{N})$ was analyzed using paired t-tests. All results are presented as the mean \pm SD of three independent experiments. Compared with adjacent hypopharyngeal tissues, HSCC tissues exhibited an apparent decrease in AIM2 protein expression and an increase in p-STAT3 protein expression and p-STAT3/STAT3 ratio. ${ }^{*} \mathrm{P}=0.0477 ;{ }^{* *} \mathrm{P}=0.0039 ;{ }^{\# \#} \mathrm{P}=0.0015$. HSCC, hypopharyngeal squamous cell carcinoma.

(http://molpath.charite.de/cutoff) (36). X-tile charts were generated for the evaluation of AIM2 and p-STAT3 expression and optimal cut-off values based on outcomes.

Statistical analysis. The ratio of the western blotting gray value of the target protein to that of the marker protein was used foR statistical analysis. Since AIM2, p-STAT3 protein expression levels and the p-STAT3/STAT3 ratio did follow a normal distribution, statistical evaluation was performed via paired t-tests. The optimal cut-off values for IHC-based expression associated with survival were determined using the online version of X-tile software (http://molpath. charite.de/cutoff). The $\chi^{2}$ or Fisher's exact tests was used to evaluate the association between AIM2 expression and clinicopathological characteristics. Survival curves were plotted using Kaplan-Meier survival analyses and compared using a log-rank test. The predictive value of the clinicopathological characteristics was evaluated using receiver operating characteristic (ROC) curve analysis. The relative risk (RR) of death associated with AIM2 expression and other variables were assessed by univariate survival analysis (log-rank test) and multivariate Cox proportional hazards regression models. Correlations between variables, ROC curves, log-rank tests and multiple Cox proportional hazards regression models were performed using SPSS statistical software (SPSS standard version 13.0; SPSS, Inc., Chicago, IL, USA). In all cases, a statistically significant difference was considered if the P-value from a two-tailed test was $<0.05$. 

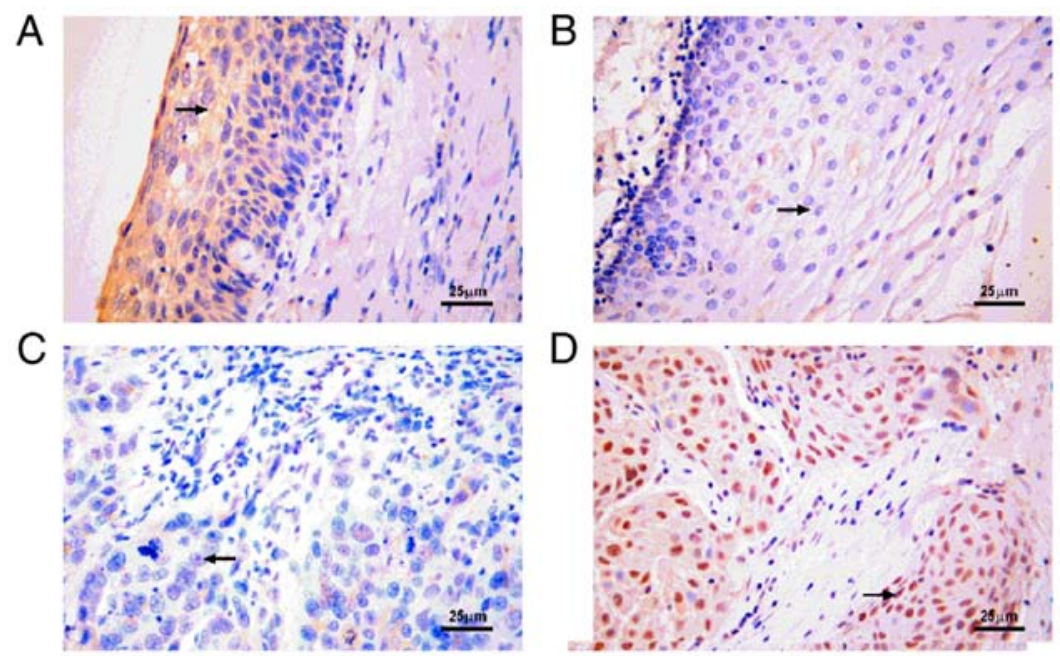

Figure 2. AIM2 and p-STAT3 expression is analyzed via IHC for 111 biopsy specimens of primary HSCC tumor tissues and 20 biopsy specimens of adjacent normal hypopharyngeal tissues. (A) AIM2 exhibited strong cytoplasmic staining in 13 of the 20 (75\%) adjacent normal hypopharyngeal tissue samples (black arrow). (B) p-STAT3 exhibited weak nuclear staining in 18 of the 20 (90\%) adjacent normal hypopharyngeal tissue samples (black arrow). (C) AIM2 exhibited weak cytoplasmic staining in 48 of the 111 (43.2\%) HSCC tissue samples (black arrow). (D) p-STAT3 exhibited strong nuclear staining in 58 of the 111 (52.3\%) HSCC tissue samples (black arrow). Original magnification, x400. Scale bars, $25 \mu \mathrm{m}$. IHC, immunohistochemistry; HSCC, hypopharyngeal squamous cell carcinoma.
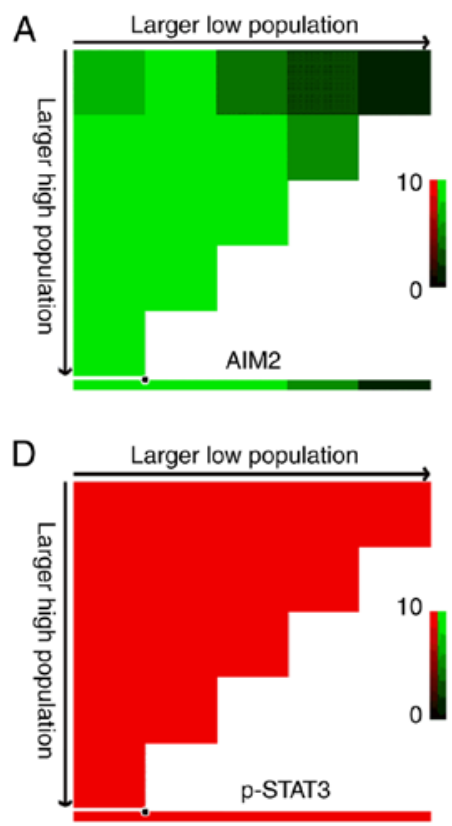

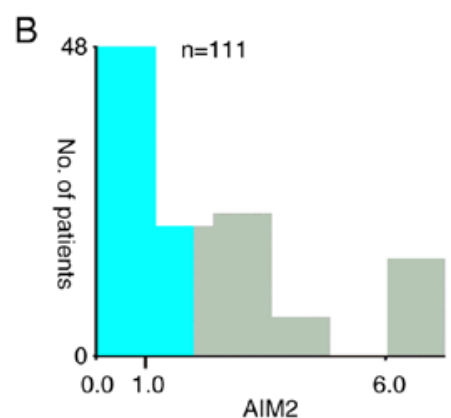

$\mathrm{E}$

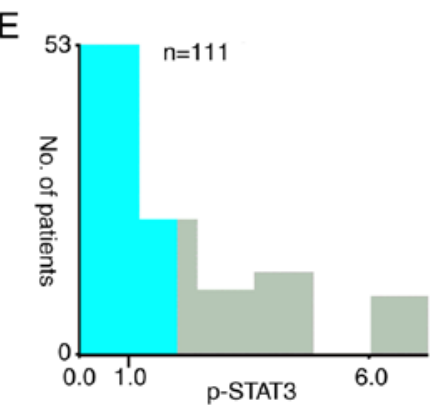

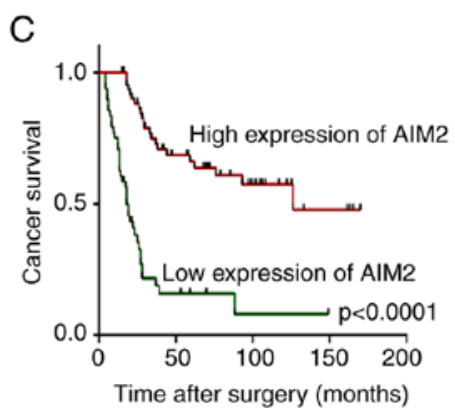

$\mathrm{F}$

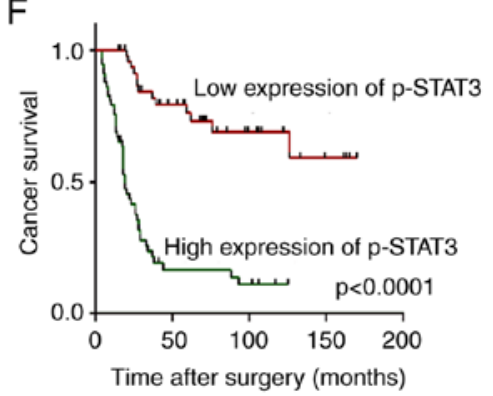

Figure 3. X-tile analysis was performed to determine the cut-off value for AIM2 and p-STAT3 expression. All HSCC cases were divided into high and low AIM2 and p-STAT3 expression groups. The diagram displays the $\chi^{2} \log$-rank values when the patients were divided into two cohorts. The optimal cut-off value $(\mathrm{H}$ score $=1$ ) highlighted by the black spot on the horizontal axis $(\mathrm{A}$ and $\mathrm{D})$ is displayed on a histogram corresponding to all patients (B and E). (C and F) AIM2 and p-STAT3 were both associated with the overall survival of HSCC patients. Kaplan-Meier survival curves for AIM2 and p-STAT3 expression in all patients are presented in C and F. HSCC, hypopharyngeal squamous cell carcinoma.

\section{Results}

Expression level of AIM2 in HSCC and adjacent normal hypopharyngeal tissues by western blot assays. In the present study, the expression of AIM2, p-STAT3 and total STAT3 proteins was detected by western blotting in 5 pairs of primary HSCC and adjacent normal hypopharyngeal tissues. Compared with those in adjacent hypopharyngeal tissues, an apparent decrease in the expression of AIM2 protein and an increase in the expression of $\mathrm{p}$-STAT3 protein and $\mathrm{p}$-STAT3/total STAT3 ratio were detected in HSCC tissues (Fig. 1).
AIM2 and p-STAT3 expression in hypopharyngeal tissues examined by IHC. AIM2 and p-STAT3 expression could be successfully and simultaneously detected by IHC in 111 HSCC and 20 normal hypopharyngeal epithelial tissues (Fig. 2). AIM2 was primarily expressed in the cytoplasm (Fig. 2A), and p-STAT3 was primarily expressed in the nucleus (Fig. 2D). Based on the X-tile program, AIM2 expression higher than the cut-off value of 1 was defined as high expression (Fig. 3A). Similarly, the cut-off score of 1 based on X-tile plots could also distinguish high or low p-STAT3 expression in the HSCC samples (Fig. 3D). In the present study, 63 (56.8\%) HSCC 
A

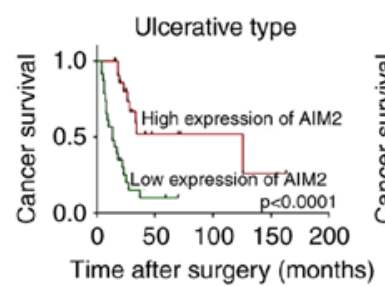

B

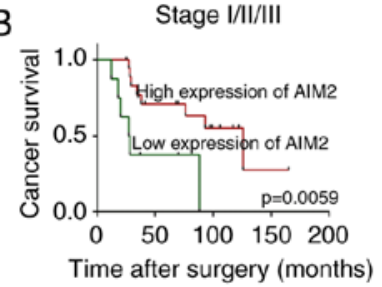

C

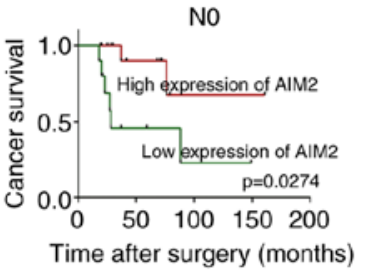

E
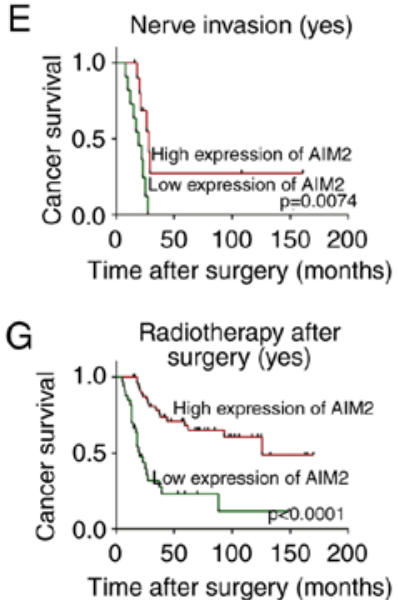
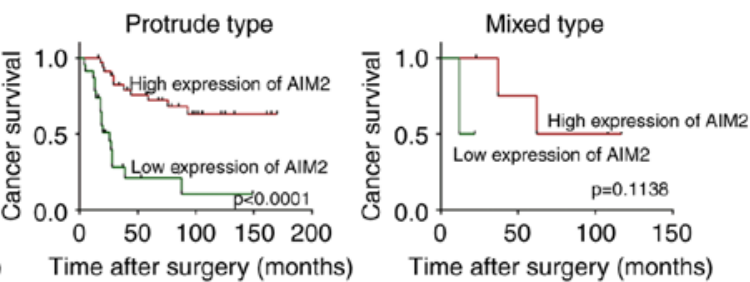

Stage IV
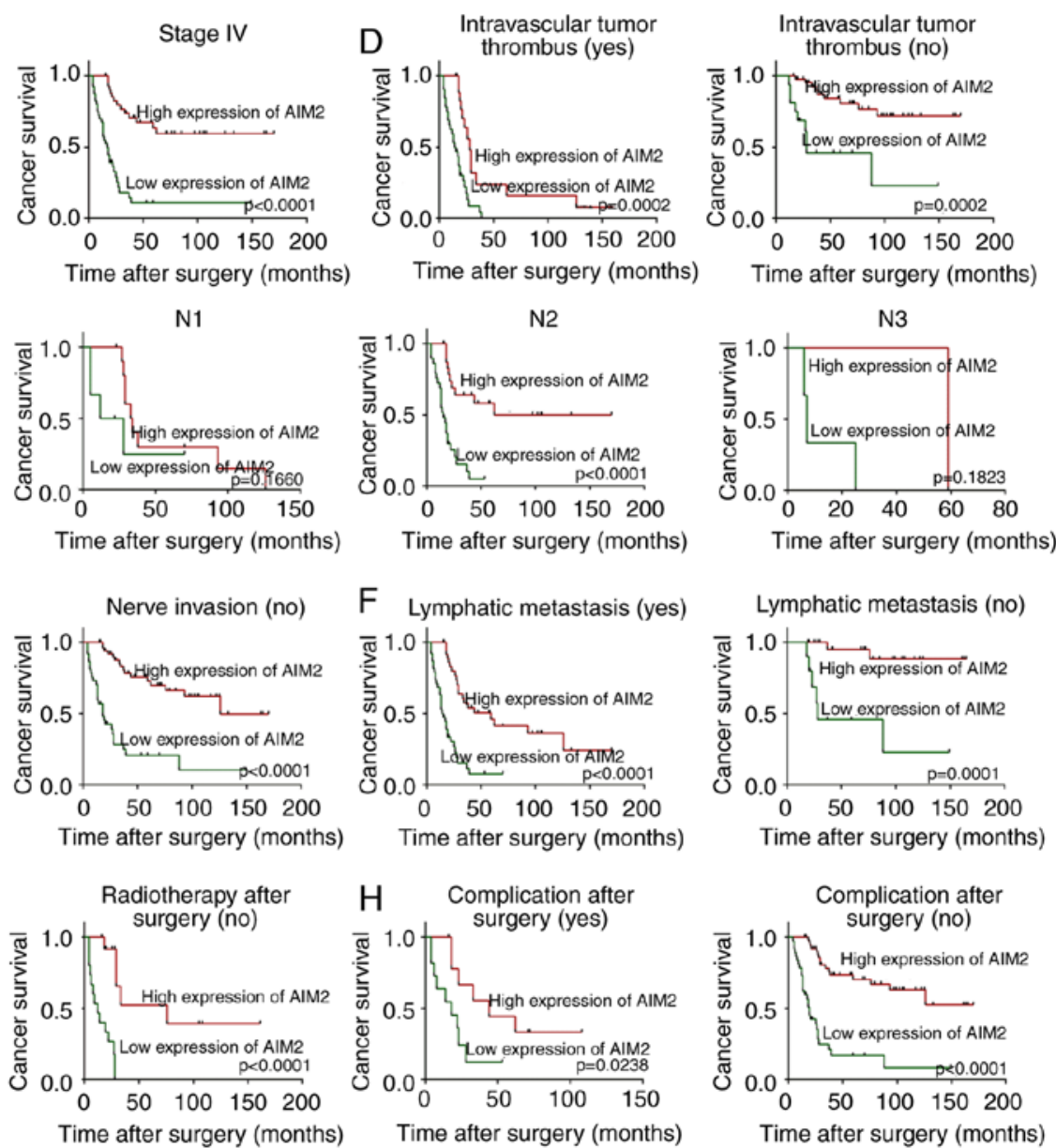
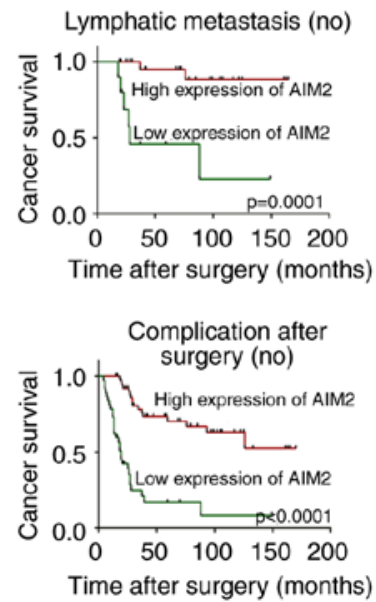

Figure 4. Kaplan-Meier survival curve analysis based on AIM2 expression in subsets of patients with HSCC (log-rank test). (A) Kaplan-Meier survival curve analysis based on AIM2 expression in subsets of patients with different growth patterns of HSCC: Ulcerative type, protruding type, and mixed type. (B) Kaplan-Meier survival curve analysis based on AIM2 expression in subsets of patients with different stages of HSCC: Stage I/II/III and stage IV. (C) Kaplan-Meier survival curve analysis based on AIM2 expression in subsets of patients with different N status of HSCC: N0, N1, N2, and N3. (D) Kaplan-Meier survival curves based on AIM2 expression in subsets of patients with or without intravascular tumor thrombus: Intravascular tumor thrombus (Yes) and intravascular tumor thrombus (No). (E) Kaplan-Meier survival curves based on AIM2 expression in subsets of patients with or without nerve invasion: nerve invasion (Yes) and nerve invasion (No). (F) Kaplan-Meier survival curve analysis based on AIM2 expression in subsets of patients with or without lymphatic metastasis: Lymphatic metastasis (Yes) and lymphatic metastasis (No). (G) Kaplan-Meier survival curves analysis based on AIM2 expression in subsets of patients with or without radiotherapy after surgery: Radiotherapy after surgery (Yes) and radiotherapy after surgery (No). (H) Kaplan-Meier survival curve analysis based on AIM2 expression in subsets of patients with or without complications after surgery: Complications after surgery (Yes) and complications after surgery (No). HSCC, hypopharyngeal squamous cell carcinoma.

cases had high expression of AIM2, 48 (43.2\%) cases had low expression of AIM2, $58(52.3 \%)$ cases had high expression of p-STAT3, and $53(47.7 \%)$ cases had low expression of p-STAT3 as determined by IHC (Fig. 2). For the 20 samples of adjacent normal hypopharyngeal tissues, high expression of AIM2 was detected in $13(75 \%)$ samples, and low expression of p-STAT3 was detected in 18 (90\%) samples (Fig. 2A and B). In addition, AIM2 expression was closely associated with intravascular tumor thrombus and lymph node metastasis $(\mathrm{P}<0.05$; Table I).

Relationship between clinicopathological characteristics, AIM2 expression and survival rate in HSCC patients.
Kaplan-Meier analysis revealed that clinicopathological characteristics including growth pattern $(\mathrm{P}=0.01)$, $\mathrm{N}$ status $(\mathrm{P}<0.0001)$, intravascular tumor thrombus $(\mathrm{P}<0.0001)$, nerve invasion $(\mathrm{P}=0.0061)$, lymphatic metastasis $(\mathrm{P}<0.0001)$ and radiotherapy after surgery $(\mathrm{P}=0.009)$, and complications after surgery $(\mathrm{P}=0.031)$ had a significant impact on patient survival (Table II). Evaluation of patient survival revealed that low expression of AIM2 was closely associated with poor survival rates $(\mathrm{P}<0.0001$; Fig. $4 \mathrm{C})$, and the mean and median survival time of patients with low expression of AIM2 were 24 and 18 months, respectively. The mean and median survival time of patients with high expression of AIM2 were 
Table II. Univariate and multivariate analyses of different prognostic features in 111 HSCC patients.

\begin{tabular}{|c|c|c|c|c|c|c|}
\hline \multirow[b]{2}{*}{ Variable } & \multicolumn{4}{|c|}{ Univariate analysis $^{\mathrm{a}}$} & \multicolumn{2}{|c|}{ Multivariate analysis ${ }^{\mathrm{b}}$} \\
\hline & $\begin{array}{c}\text { All } \\
\text { patients }\end{array}$ & $\begin{array}{c}\text { Mean } \\
\text { survival (months) }\end{array}$ & $\begin{array}{c}\text { Median } \\
\text { survival (months) }\end{array}$ & P-value & $\operatorname{HR}(95 \% \mathrm{CI})$ & P-value \\
\hline Age at surgery & & & & 0.408 & & \\
\hline$<60$ & 48 & 51.7 & 44 & & & \\
\hline$\geq 60$ & 63 & 41.2 & 37 & & & \\
\hline Side & & & & 0.432 & & \\
\hline Left & 55 & 43.7 & 38 & & & \\
\hline Right & 56 & 47.8 & 37 & & & \\
\hline Sex & & & & 0.004 & $0.830(0.266-2.587)$ & 0.748 \\
\hline Male & 93 & 40.4 & 29 & & & \\
\hline Female & 18 & 73.3 & UD & & & \\
\hline Site of primary tumor & & & & 0.060 & & \\
\hline Postcricoidregion & 6 & 79 & UD & & & \\
\hline Posterior pharyngeal wall & 21 & 47.7 & 33 & & & \\
\hline Pyriform sinus & 84 & 42.9 & 37 & & & \\
\hline Histological grade & & & & 0.202 & & \\
\hline I (well) & 18 & 62.9 & 88 & & & \\
\hline II (moderate) & 68 & 46.5 & 29 & & & \\
\hline III (poor) & 25 & 31.5 & 28 & & & \\
\hline Tumor size $\left(\mathrm{cm}^{2}\right)$ & & & & 0.798 & & \\
\hline$<6$ & 29 & 40.4 & 39 & & & \\
\hline$\geq 6$ & 82 & 47.7 & 37 & & & \\
\hline Growth pattern & & & & 0.010 & $1.420(0.779-2.591)$ & 0.252 \\
\hline Ulcerative & 46 & 29.4 & 25 & & & \\
\hline Protruding & 58 & 45.8 & 88 & & & \\
\hline Mixed & 7 & 54.4 & 62 & & & \\
\hline Tumor stage & & & & & & \\
\hline T status & & & & 0.830 & & \\
\hline $\mathrm{T} 1$ & 2 & 52 & 52 & & & \\
\hline $\mathrm{T} 2$ & 15 & 45.5 & 62 & & & \\
\hline $\mathrm{T} 3$ & 43 & 46.4 & 34 & & & \\
\hline $\mathrm{T} 4$ & 51 & 45.0 & 37 & & & \\
\hline $\mathrm{N}$ status & & & & $<0.0001$ & $1.636(1.107-2.417)$ & $0.014^{\mathrm{c}}$ \\
\hline N0 & 35 & 71.5 & UD & & & \\
\hline N1 & 17 & 39.5 & 29 & & & \\
\hline $\mathrm{N} 2$ & 55 & 32.9 & 22 & & & \\
\hline N3 & 4 & 24.3 & 16 & & & \\
\hline Clinical stage & & & & 0.127 & & \\
\hline Stage I/II/III & 27 & 62.6 & 88 & & & \\
\hline Stage IV & 84 & 40.4 & 29 & & & \\
\hline Depth of invasion & & & & 0.076 & & \\
\hline Submucosa & 47 & 53.5 & 88 & & & \\
\hline Muscular layer & 46 & 46.4 & 34 & & & \\
\hline External laryngeal tissue & 18 & 24 & 27 & & & \\
\hline Intravascular tumor thrombus & & & & $<0.0001$ & $0.225(0.110-0.458)$ & $<0.0001^{\mathrm{c}}$ \\
\hline Yes & 51 & 23.6 & 19 & & & \\
\hline No & 60 & 64.6 & UD & & & \\
\hline Nerve invasion & & & & 0.0061 & $1.253(0.581-2.703)$ & 0.565 \\
\hline Yes & 22 & 30.5 & 23 & & & \\
\hline No & 89 & 49.5 & 62 & & & \\
\hline
\end{tabular}


Table II. Continued.

\begin{tabular}{|c|c|c|c|c|c|c|}
\hline \multirow[b]{2}{*}{ Variable } & \multicolumn{4}{|c|}{ Univariate analysis $^{\mathrm{a}}$} & \multicolumn{2}{|c|}{ Multivariate analysis ${ }^{\mathrm{b}}$} \\
\hline & $\begin{array}{c}\text { All } \\
\text { patients }\end{array}$ & $\begin{array}{c}\text { Mean } \\
\text { survival (months) }\end{array}$ & $\begin{array}{c}\text { Median } \\
\text { survival (months) }\end{array}$ & P-value & $\mathrm{HR}(95 \% \mathrm{CI})$ & P-value \\
\hline Lymphatic metastasis & & & & $<0.0001$ & $1.465(0.277-7.761)$ & 0.654 \\
\hline Yes & 76 & 33.9 & UD & & & \\
\hline No & 35 & 71.5 & 26 & & & \\
\hline Radiotherapy after surgery & & & & 0.009 & $1.817(0.804-4.107)$ & 0.151 \\
\hline Yes & 83 & 50.6 & 62 & & & \\
\hline No & 28 & 31.4 & 28 & & & \\
\hline Complications after surgery & & & & 0.031 & $0.735(0.378-1.730)$ & 0.364 \\
\hline Yes & 21 & 31.8 & 23 & & & \\
\hline No & 90 & 49.0 & 59 & & & \\
\hline AIM2 & & & & $<0.0001$ & $0.353(0.188-0.663)$ & $0.0012^{\mathrm{c}}$ \\
\hline Low expression & 48 & 24.0 & 18 & & & \\
\hline High expression & 63 & 62.4 & 126 & & & \\
\hline p-STAT3 & & & & $<0.0001$ & $4.093(2.076-8.071)$ & $<0.0001^{\mathrm{c}}$ \\
\hline Low expression & 53 & 65.2 & UD & & & \\
\hline High expression & 58 & 28.0 & 19 & & & \\
\hline
\end{tabular}

${ }^{\mathrm{a}}$ Log-rank test; ${ }^{\mathrm{b}} \mathrm{Cox}$ regression model; ${ }^{\mathrm{c}}$ Final P-value of the Cox regression model; HSCC, hypopharyngeal squamous cell carcinoma; HR, hazard ratio; $\mathrm{CI}$, confidence interval; $\mathrm{UD}$, undefined.

62.4 and 126 months, respectively (Table II). Moreover, survival analysis in patients with high or low expression of AIM2 was performed based on the growth pattern, clinical stage, $\mathrm{N}$ status, intravascular tumor thrombus, lymphatic metastasis, nerve invasion, radiotherapy after surgery, and complications after surgery. The results demonstrated that the factors associated with poor prognosis in HSCC patients with low expression of AIM2 included ulcerative type growth $(\mathrm{P}<0.0001 ; \mathrm{Fig} .4 \mathrm{~A})$, protruding type growth ( $\mathrm{P}<0.0001$; Fig. 4A), stage I/II/III ( $\mathrm{P}=0.0059$; Fig. 4B), stage IV $(\mathrm{P}<0.0001$; Fig. 4B), N0 ( $\mathrm{P}=0.0274$; Fig. 4C), N2 ( $\mathrm{P}<0.0001$; Fig. 4C), intravascular tumor thrombus (Yes) $(\mathrm{P}=0.0002$; Fig. 4D), intravascular tumor thrombus (No) $(\mathrm{P}=0.0002$; Fig. 4D), nerve invasion (Yes) $(\mathrm{P}=0.0074$; Fig. 4E), nerve invasion (No) $(\mathrm{P}<0.0001$; Fig. 4E), lymphatic metastasis (Yes) $(\mathrm{P}<0.0001$; Fig. 4F), lymphatic metastasis (No) $(\mathrm{P}=0.0001$; Fig. 4F), radiotherapy after surgery (Yes) $(\mathrm{P}<0.0001$; Fig. 4G), radiotherapy after surgery (No) $(\mathrm{P}<0.0001$; Fig. 4G), complications after surgery (Yes) $(\mathrm{P}=0.0238$; Fig. $4 \mathrm{H})$ and complications after surgery (No) $(\mathrm{P}<0.0001$; Fig. 4H).

Multivariate survival analysis of independent prognostic factors of HSCC. Multivariate Cox proportional hazards regression analysis was performed to assess the independent value of each variable in predicting the survival of HSCC patients (Table II). After AIM2 expression and clinicopathological characteristics (including sex, growth pattern, $\mathrm{N}$ status, intravascular tumor thrombus, nerve invasion, lymphatic metastasis, radiotherapy after surgery and complications after surgery) were analyzed by univariate log-rank tests, the factors that were significantly associated with the overall survival rate were included in a multivariate Cox analysis (Table II). As anticipated, low expression of AIM2 protein was an independent risk factor for HSCC patients with poor prognosis [RR, 0.353; confidence interval $(\mathrm{CI}), 0.188-0.663 ; \mathrm{P}=0.0012]$. With respect to other features, only $\mathrm{N}$ status $(\mathrm{P}=0.014$; Table II $)$ and intravascular tumor thrombus $(\mathrm{P}<0.0001$; Table II) were independent prognostic predictors for the survival of HSCC patients.

Correlation between the expression levels of AIM2 and p-STAT3 in HSCC. Western blot assays revealed an inverse association between the expression levels of AIM2 and p-STAT3 proteins in HSCC (Fig. 1A). Using the criteria described earlier, high expression of p-STAT3 was detected in 58/111 (52.3\%) cases in our HSCC cohort by IHC. Further analysis revealed a significant inverse association between AIM2 and p-STAT3 expression in HSCC patients $(\mathrm{P}<0.0001$, Fisher's exact test; Table I and Fig. 2C and D).

Correlation of low expression of AIM2 combined with high expression of p-STAT3 with poor prognosis in HSCC patients. To further confirm whether the expression of p-STAT3 can affect AIM2-related prognosis, we divided the HSCC cases into a low p-STAT3 expression (low p-STAT3) group and a high p-STAT3 expression (high p-STAT3) group based on the optimal cut-off of the p-STAT3 expression index. When all cases of HSCC were stratified by the p-STAT3 expressioN status, patients with low AIM2 expression had a 
A

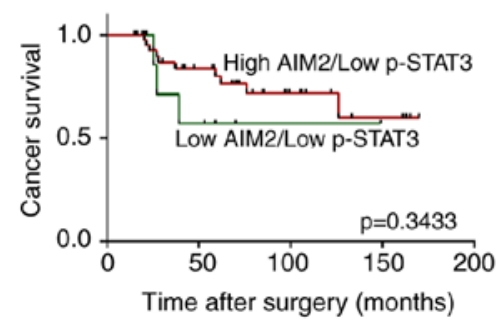

B

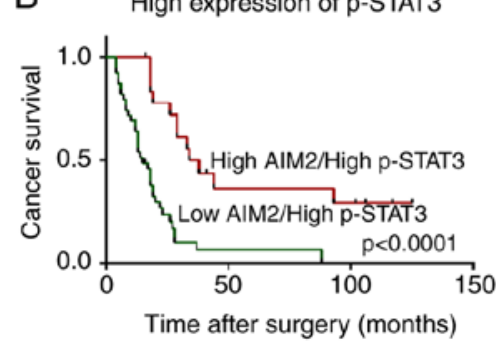

C

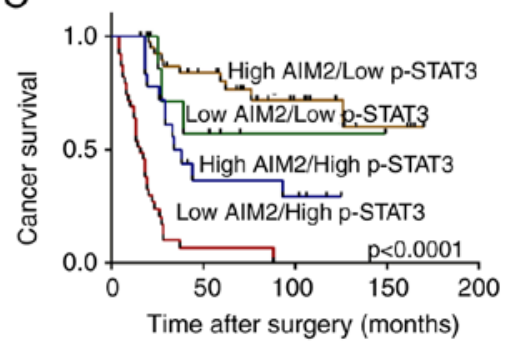

Figure 5. Expression patterns of AIM2 and p-STAT3 in HSCC, and Kaplan-Meier survival curve analysis. (A) Kaplan-Meier survival curve analysis of the influence of AIM2 expression on the survival of patients with low p-STAT3 expression. (B) Kaplan-Meier survival curve analysis of the influence of AIM2 expression on the survival of patients with high p-STAT3 expression. (C) Combined analysis of the influence of AIM2 and p-STAT3 expression on the survival rates of HSCC patients (log-rank test). HSCC, hypopharyngeal squamous cell carcinoma.
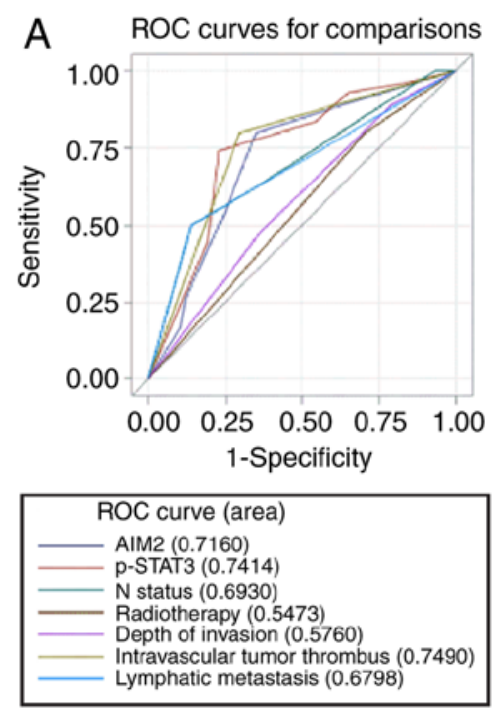

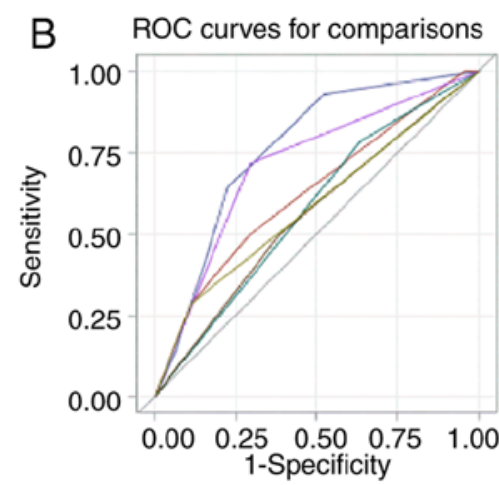

ROC curve (area) AIM2 (0.7597) $\mathrm{N}$ status $(0.6274)$ Radiotherapy $(0.5747)$ Depth of invasion (0.5584) Intravascular tumor thrombus $(0.7094)$ Lymphatic metastasis $(0.5860)$

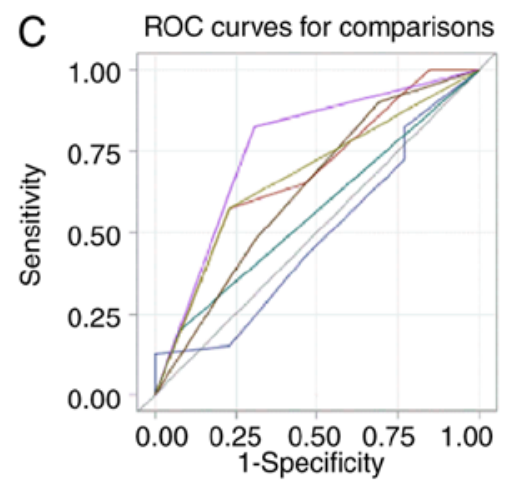

ROC curve (area)

AIM2 (0.4856)

$\mathrm{N}$ status $(0.6788)$

Radiotherapy $(0.5615)$

Depth of invasion (0.6298)

Intravascular tumor thrombus $(0.7587)$

Lymphatic metastasis $(0.6721)$

Figure 6. ROC curves based on different clinicopathological characteristics and AIM2 expression were analyzed to assess the relationship between these features and survival status. (A) For all patients, AIM2 expression [area under the curve (AUC) $=0.7160, \mathrm{P}=0.0011$ ), $\mathrm{p}$-STAT3 (AUC $=0.7414, \mathrm{P}<0.0001$ ), $\mathrm{N}$ status (AUC=0.6930, $\mathrm{P}=0.0002$ ), radiotherapy after surgery ( $\mathrm{AUC}=0.5473, \mathrm{P}=0.2539$ ), depth of invasion (AUC=0.5760, $\mathrm{P}=0.1226$ ), intravascular tumor thrombus ( $\mathrm{AUC}=0.7490, \mathrm{P}<0.0001$ ), and lymphatic metastasis ( $\mathrm{AUC}=0.6798, \mathrm{P}=0.0001$ ) were significantly associated with survival. (B) In the high $\mathrm{p}-\mathrm{STAT} 3$ expression group, AIM2 expression ( $\mathrm{AUC}=0.7597, \mathrm{P}=0.0202$ ), $\mathrm{N}$ status ( $\mathrm{AUC}=0.6274, \mathrm{P}=0.0907$ ), radiotherapy after surgery $(\mathrm{AUC}=0.5747, \mathrm{P}=0.3062)$, depth of invasion ( $\mathrm{AUC}=0.5584, \mathrm{P}=0.4955$ ), intravascular tumor thrombus ( $\mathrm{AUC}=0.7094, \mathrm{P}=0.0084$ ), and lymphatic metastasis $(\mathrm{AUC}=0.5860, \mathrm{P}=0.1337$ ) were employed to predict survival. (C) In the low p-STAT3 expression group, AIM2 expression (AUC=0.4856, $\mathrm{P}=0.8953$ ), $\mathrm{N}$ status (AUC=0.6788, $\mathrm{P}=0.0388$ ), radiotherapy after surgery ( $\mathrm{AUC}=0.5615, \mathrm{P}=0.3238$ ), depth of invasion $(\mathrm{AUC}=0.6298, \mathrm{P}=0.1069$ ), intravascular tumor thrombus $(\mathrm{AUC}=0.7587, \mathrm{P}=0.0012$ ), and lymphatic metastasis (AUC=0.6721, $\mathrm{P}=0.0396$ ) were analyzed to assess survival durations. $\mathrm{ROC}$, receiver operating characteristic.

significantly poorer prognosis than patients with high AIM2 expression in the high $\mathrm{p}-\mathrm{STAT} 3$ group $(\mathrm{P}<0.0001$; Fig. 5B). However, no significant difference in survival time was found between patients with low and high AIM2 expression in the low p-STAT3 group ( $\mathrm{P}=0.3433$; Fig. 5A). In the combined analysis of AIM2 and p-STAT3 expression, the low AIM2/high p-STAT3 group had the worst survival (mean survival time, 17.6 months; median survival time, 15 months), the high AIM2/high p-STAT3 group and the low AIM2/low p-STAT3 group had moderate survival (mean survival time, 49.5 and 51.4 months, respectively), and the high AIM2/low p-STAT3 group had the best survival (mean survival time, 68.0 months, $\mathrm{P}<0.0001$; Fig. 5C).

To evaluate the prognostic value of AIM2 expression in all HSCC patients, we used ROC curves to assess the survival rates of patients with high and low p-STAT3 expression. The results confirmed the prospective predictive significance of AIM2 with respect to specific survival in all HSCC patients (AUC=0.7160; Fig. 6A). Upon further analysis in the group with high p-STAT3 expression, AIM2 was identified as a significant prognostic factor associated with the survival of HSCC patients (AUC $=0.7597, \mathrm{P}<0.0001$; Fig. 6B). In contrast, AIM2 had no statistical association with survival in the group with low p-STAT3 expression (AUC $=0.4856$, $\mathrm{P}=0.272$; Fig. 6C).

\section{Discussion}

In HSCC, the biological effects and mechanisms of AIM2 on tumor cells are unclear. Two theories have been put forward to explain these effects. In one theory, AIM2 acts as a danger signal receptor in the innate immune system and forms an inflammatory complex, and, subsequently, the AIM2 inflammasome promotes the maturation of cytokines mediated by caspase-1 and triggers cell death in innate immune cells, resulting in pro-IL-1 $\beta$ cleavage and IL-1 $\beta$ secretion $(8,9)$. 
Tumor-derived IL-1 $\beta$ can inhibit tumor growth and local recurrence by recruiting neutrophils (14). In another theory, AIM2 inhibits tumor growth in colon tumors independent of the function of inflammatory proteins, but it can inhibit tumor growth by suppressing the activity of Akt (37). AIM2 inhibits the growth of colon tumors by reducing the proliferation of colon epithelial stem cells (38) and possibly by controlling the composition of the intestinal flora (39). These findings suggest that the loss of AIM2 protein in tumor cells may provide favorable conditions for the growth of cancer cells.

In the present study, 5 cases of fresh HSCC and adjacent normal hypopharyngeal tissues were assessed by western blotting, and the expression levels of AIM2 and p-STAT3 in 111 cases of surgically resected paraffin-embedded HSCC tissues were analyzed by IHC. The western blot results revealed that AIM2 levels were significantly lower in HSCC tissues than in adjacent normal hypopharyngeal epithelial tissues. Reduced expression of AIM2 has often been observed in other types of cancer, such as colon (10) and prostate cancer (15), small cell lung cancer and adenocarcinoma (17), and poorly differentiated squamous cell carcinoma. These data suggest that decreased expression of AIM2 may play an important role in certain types of human cancers, including HSCC. However, the expression of AIM2 is increased in nasopharyngeal carcinoma $(14,16)$, oral squamous cell carcinoma (18) and lung adenocarcinoma (17). The varying expression levels of AIM2 in different tumor tissues suggest that AIM2 may play unique roles in different types of cancers.

Our findings also revealed that the expression of AIM2 in our HSCC cohort was associated with intravascular tumor thrombus and lymph node metastasis. These results indicated that the decreased expression of AIM2 in HSCC may contribute to an increase in the malignant phenotype of tumors. Similar results were obtained in other human malignancies such as colon cancer, prostate cancer and nasopharyngeal carcinoma, and the decrease in or deficiency of AIM2 expression was often correlated with more aggressive phenotypes and poor prognosis $(10,14,15)$. However, in a study of cutaneous squamous cell carcinoma (cSCC), the knockdown of AIM2 resulted in decrease in the viability of cSCC cells, initiation of apoptosis, decrease in cell invasion and downregulation of the invasion-associated proteases MMP1 and MMP13. Moreover, AIM2 inhibited tumor growth and angiogenesis in skin squamous cell carcinoma (SCC). Patsos et al found that the overexpression of AIM2 can increase cellular adhesion and invasion and promote migration (40). These results clearly contradict our data. As suggested by studies from numerous other research groups, AIM2 can be described as a 'double-edged sword', with both excessive expression and inhibition of AIM2 promoting the occurrence and development of cancer $(38,40)$. Therefore, we speculate that the regulation of AIM2 expression affects the expression of metastasis-related proteins, but the specific mechanism is not very clear and will be our future research direction.

In our study, we found that low expression of AIM2 was a robust and independent factor associated with poor prognosis in HSCC patients. Notably, survival analysis-based growth pattern, clinical stage, $\mathrm{N}$ status, intravascular tumor thrombus, lymphatic metastasis, nerve invasion, radiotherapy after surgery, and complications after surgery revealed that AIM2 expression was closely related to the survival of different subsets of HSCC patients. Therefore, AIM2 expression may be a potential factor for predicting the clinical prognoses of patients with HSCC. Our data suggested that the detection of AIM2 expression by IHC could serve as an effective tool to determine the risk of invasion and/or progression of HSCC.

IHC revealed that the high expression of p-STAT3 was closely associated with short survival times in HSCC patients. This result was consistent with previous findings (32). Further analysis revealed that the expression of AIM2 in the HSCC cohort was negatively correlated with p-STAT3 expression. To determine whether the changes in p-STAT3 expression could affect the prognosis related to AIM2, we evaluated the survival of HSCC patients stratified by p-STAT3 expression and found that low AIM2 expression was closely related to poor prognosis in the group with high p-STAT3 expression but not in the group with low p-STAT3 expression. This result was confirmed by ROC curve analyses, which revealed that AIM2 was significantly associated with the prognosis of patients in the group with high p-STAT3 expression. In addition, when the expression of AIM2 was analyzed in combination with that of p-STAT3, the survival rate of the patients in the low AIM2/high p-STAT3 group was the lowest among all groups. Previous studies have shown that the deletion of AIM2 can promote the overexpression of IL-22 and enhance the activation of STAT3 by regulating IL-18 production in drug-induced colitis in Aim $2^{--}$mice (41). Moreover, in Aim $2^{-/}$mice, continued activation of STAT3 and Akt promoted the proliferation of intestinal crypt cells and could contribute to the increase in the susceptibility to colon cancer (41). In most cases, there is an inflammatory environment around the HSCC tissues. Therefore, we speculate that AIM2 may regulate the expression of p-STAT3 through the IL-18/IL-22 pathways in HSCC, but the specific mechanism requires further investigation.

In summary, the present study demonstrated the pattern of AIM2 expression in normal hypopharyngeal tissues and HSCC tissues. The results revealed that the reduced expression of AIM2 may confer a malignant phenotype in HSCC cells. In addition, our research indicated that the decreased expression of AIM2 protein in HSCC may be a new independent prognostic marker, and more importantly, the expression of AIM2 combined with p-STAT3 in tumor cells can predict the prognosis of tumor patients.

Although the specimens age ranged over a 12-year period, we also believe that there is no correlation between specimen age and antigen expression level. Furthermore, our study design and protocols could minimize this correlation even if it does exist. First, we have a standard protocol for paraffin specimen preparation in which there is a very small and almost the same time lag from specimen cutting to embedding for each tumor sample. Second, antigen retrieval methods were routinely conducted prior to immunohistochemical staining. Third, although samples were obtained at different times from the patients enrolled in the present study, these patients' clinical and pathological stages were extremely similar and comparable. Finally, we found no correlation between antigen expression level and specimen age, in pre-experimental tests before we conducted formal and systematic immunohistochemical study. 
However, our study has some limitations. First, only a small number of HSCC samples were used in our study. Second, AIM2 and p-STAT3 levels were not quantitatively analyzed. Third, although our study provided important information on the involvement of AIM2 in metastasis and invasion of tumors, further experiments are required to determine the specific mechanisms underlying the role of AIM2 in the metastasis and invasion of HSCC.

\section{Acknowledgements}

Not applicable.

\section{Funding}

The present study was supported in part by a grant from the Research Foundation of Bethune International Peace Hospital (201706) and the Key Research and Development Project Plan of Hebei Provincial Science and Technology Department (no. 18277736D).

\section{Availability of data and materials}

The datasets analyzed during the present study are available from the corresponding author upon reasonable request.

\section{Authors' contributions}

ZL and XL conceived and designed the study. ZL, XS and XL contributed to the acquisition, the analysis and interpretation of the data. ZL, HL and WW performed the experiments and were involved in drafting the manuscript. All authors have read and approved the final manuscript and agree to be responsible for all aspects of the study to ensure that questions about any aspects of the work are properly investigated or resolved.

\section{Ethics approval and consent to participate}

The study protocol was approved by the Ethics Committee board of Bethune International Peace Hospital of PLA, and the need for individual patient consent was waived.

\section{Patient consent for publication}

Not applicable.

\section{Competing interests}

The authors state that they have no competing interests.

\section{References}

1. Torre LA, Bray F, Siegel RL, Ferlay J, Lortet-Tieulent J and Jemal A: Global cancer statistics, 2012. CA Cancer J Clin 65: 87-108, 2015

2. Wang YL, Feng SH, Zhu J, Zhu GP, Li DS, Wang Y, Zhu YX, Sun GH and Ji QH: Impact of lymph node ratio on the survival of patients with hypopharyngeal squamous cell carcinoma: A population-based analysis. PLoS One 8: e56613, 2013.

3. Hall SF, Groome PA, Irish J and O'Sullivan B: The natural history of patients with squamous cell carcinoma of the hypopharynx. Laryngoscope 118: 1362-1371, 2008.
4. Brown JM and Wilson WR: Exploiting tumour hypoxia in cancer treatment. Nat Rev Cancer 4: 437-447, 2004.

5. Boyle P and Ferlay J: Cancer incidence and mortality in Europe 2004. Ann Oncol 16: 481-488, 2005.

6. Takes RP, Strojan P, Silver CE, Bradley PJ, Haigentz M Jr, Wolf GT, Shaha AR, Hartl DM, Olofsson J, Langendijk JA, et al: Current trends in initial management of hypopharyngeal cancer: The declining use of open surgery. Head Neck 34: 270-281, 2012.

7. Hanahan D and Weinberg RA: Hallmarks of cancer: The next generation. Cell 144: 646-674, 2011.

8. Fernandes-Alnemri T, Yu JW, Datta P, Wu J and Alnemri ES: AIM2 activates the inflammasome and cell death in response to cytoplasmic DNA. Nature 458: 509-513, 2009.

9. Hornung V, Ablasser A, Charrel-Dennis M, Bauernfeind F, Horvath G, Caffrey DR, Latz E and Fitzgerald KA: AIM2 recognizes cytosolic dsDNA and forms a caspase-1-activating inflammasome with ASC. Nature 458: 514-518, 2009.

10. Dihlmann S, Tao S, Echterdiek F, Herpel E, Jansen L, ChangClaude J, Brenner H, Hoffmeister M and Kloor M: Lack of Absent in Melanoma 2 (AIM2) expression in tumor cells is closely associated with poor survival in colorectal cancer patients. Int J Cancer 135: 2387-2396, 2014.

11. Schulmann K, Brasch FE, Kunstmann E, Engel C, PagenstecherC, Vogelsang H, Krüger S, Vogel T, Knaebel HP, Rüschoff J, et al: HNPCC-associated small bowel cancer: Clinical and molecular characteristics. Gastroenterology 128: 590-599, 2005.

12. Woerner SM, Kloor M, Schwitalle Y, Youmans H, Doeberitz Mv, Gebert J and Dihlmann S: The putative tumor suppressor AIM2 is frequently affected by different genetic alterations in microsatellite unstable colon cancers. Genes Chromosomes Cancer 46: 1080-1089, 2007.

13. Kim TM, Laird PW and Park PJ: The landscape of microsatellite instability in colorectal and endometrial cancer genomes. Cell 155: 858-868, 2013.

14. Chen LC, Wang LJ, Tsang NM, Ojcius DM, Chen CC, Ouyang CN, Hsueh C, Liang Y, Chang KP, Chen CC, et al: Tumour inflammasome-derived IL-1 $\beta$ recruits neutrophils and improves local recurrence-free survival in EBV-induced nasopharyngeal carcinoma. EMBO Mol Med 4: 1276-1293, 2012.

15. Ponomareva L, Liu H, Duan X, Dickerson E, Shen H, Panchanathan $R$ and Choubey D: AIM2, an IFN-inducible cytosolic DNA sensor, in the development of benign prostate hyperplasia and prostate cancer. Mol Cancer Res 11: 1193-1202, 2013.

16. Wang LJ, Hsu CW, Chen CC, Liang Y, Chen LC, Ojcius DM, Tsang NM, Hsueh C, Wu CC and Chang YS: Interactome-wide analysis identifies end-binding protein 1 as a crucial component for the speck-like particle formation of activated absence in melanoma 2 (AIM2) inflammasomes. Mol Cell Proteomics 11: 1230-1244, 2012.

17. Kong $\mathrm{H}$, Wang $\mathrm{Y}$, Zeng $\mathrm{X}$, Wang $\mathrm{Z}$, Wang $\mathrm{H}$ and $\mathrm{Xie} \mathrm{W}$ : Differential expression of inflammasomes in lung cancer cell lines and tissues. Tumour Biol 36: 7501-7513, 2015.

18. Kondo Y, Nagai K, Nakahata S, Saito Y, Ichikawa T, Suekane A, Taki T, Iwakawa R, Enari M, Taniwaki M, et al: Overexpression of the DNA sensor proteins, absent in melanoma 2 and interferon-inducible 16, contributes to tumorigenesis of oral squamous cell carcinoma with p53 inactivation. Cancer Sci 103: 782-790, 2012.

19. Sánchez A, Nagy P and Thorgeirsson SS: STAT-3 activity in chemically-induced hepatocellular carcinoma. Eur J Cancer 39: 2093-2098, 2003.

20. Zhou T, Chao L, Rong G, Wang C, Ma R and Wang X: Down-regulation of GRIM-19 is associated with STAT3 overexpression in breast carcinomas. Hum Pathol 44: 1773-1779, 2013.

21. Kim SM, Kwon OJ, Hong YK, Kim JH, Solca F, Ha SJ, Soo RA, Christensen JG, Lee JH and Cho BC: Activation of IL-6R/JAK1/STAT3 signaling induces de novo resistance to irreversible EGFR inhibitors in non-small cell lung cancer with T790M resistance mutation. Mol Cancer Ther 11: 2254-2264, 2012.

22. Abdulghani J, Gu L, Dagvadorj A, Lutz J, Leiby B, Bonuccelli G, Lisanti MP,Zellweger T, Alanen K, Mirtti T, et al: Stat3 promotes metastatic progression of prostate cancer. Am J Pathol 172: $1717-1728,2008$

23. Grandis JR, Drenning SD, Chakraborty A, Zhou MY, Zeng Q, Pitt AS and Tweardy DJ: Requirement of Stat 3 but not Stat1 activation for epidermal growth factor receptor-mediated cell growth in vitro. J Clin Invest 102: 1385-1392, 1998. 
24. Sahu RP and Srivastava SK: The role of STAT-3 in the induction of apoptosis in pancreatic cancer cells by benzyl isothiocyanate. J Natl Cancer Inst 101: 176-193, 2009.

25. Guo C, Yang G, Khun K, Kong X, Levy D, Lee P and Melamed J: Activation of Stat3 in renal tumors. Am J Transl Res 1: 283-290, 2009.

26. Lin TS, Mahajan S and Frank DA: STAT signaling in the pathogenesis and treatment of leukemias. Oncogene 19: 2496-2504, 2000.

27. Corvinus FM, Orth $\mathrm{C}$, Moriggl R, Tsareva SA, Wagner S, Pfitzner EB, Baus D, Kaufmann R, Huber LA, Zatloukal K, et al: Persistent STAT3 activation in colon cancer is associated with enhanced cell proliferation and tumor growth. Neoplasia 7 : $545-555,2005$

28. Yu CL, Jove R and Burakoff SJ: Constitutive activation of the Janus kinase-STAT pathway in T lymphoma overexpressing the Lck protein tyrosine kinase. J Immunol 159: 5206-5210, 1997.

29. Niu G, Bowman T, Huang M, Shivers S, Reintgen D, Daud A Chang A, Kraker A, Jove R and Yu H: Roles of activated Src and Stat3 signaling in melanoma tumor cell growth. Oncogene 21: 7001-7010, 2002.

30. Rahaman SO,HarborPC,Chernova O,Barnett GH, Vogelbaum MA and Haque SJ: Inhibition of constitutively active Stat 3 suppresses proliferation and induces apoptosis in glioblastoma multiforme cells. Oncogene 21: 8404-8413, 2002.

31. Darnell JE: Validating Stat3 in cancer therapy. Nat Med 11: 595-596, 2005.

32. Masuda M, Suzui M, Yasumatu R, Nakashima T, Kuratomi Y, Azuma K, Tomita K, Komiyama S and Weinstein IB: Constitutive activation of signal transducers and activators of transcription 3 correlates with cyclin D1 overexpression and may provide a novel prognostic marker in head and neck squamous cell carcinoma Cancer Res 62: 3351-3355, 2002.
33. Leeman RJ, Lui VW and Grandis JR: STAT3 as a therapeutic target in head and neck cancer. Expert Opin Biol Ther 6: 231-241, 2006.

34. Lai SY and Johnson FM: Defining the role of the JAK-STAT pathway in head and neck and thoracic malignancies: Implications for future therapeutic approaches. Drug Resist Updat 13: 67-78, 2010.

35. Lin WW and Karin M: A cytokine-mediated link between innate immunity, inflammation, and cancer. J Clin Invest 117: 1175-1183, 2007.

36. Budczies J, Klauschen F, Sinn BV, Győrffy B, Schmitt WD, Darb-Esfahani S and Denkert C: Cutoff Finder: A comprehensive and straightforward Web application enabling rapid biomarker cut-off optimization. PLoS One 7: e51862, 2012.

37. Wilson JE, Petrucelli AS, Chen L, Koblansky AA, Truax AD, Oyama Y, Rogers AB, Brickey WJ, Wang Y, Schneider M, et al: Inflammasome-independent role of AIM2 in suppressing colon tumorigenesis via DNA-PK and Akt. Nat Med 21: 906-913, 2015.

38. Man SM, Zhu Q, Zhu L, Liu Z, Karki R, Malik A, Sharma D, Li L, Malireddi RK, Gurung P, et al: Critical role for the DNA sensor AIM2 in stem cell proliferation and cancer. Cell 162: 45-58, 2015

39. AIM2 blocks colon cancer in three ways. Cancer Discov 5: 899-900, 2015.

40. Patsos G, Germann A, Gebert J and Dihlmann S: Restoration of absent in melanoma 2 (AIM2) induces G2/M cell cycle arrest and promotes invasion of colorectal cancer cells. Int J Cancer 126: $1838-1849,2010$

41. Ratsimandresy RA, Indramohan M, Dorfleutner A and Stehlik C: The AIM2 inflammasome is a central regulator of intestinal homeostasis through the IL-18/IL-22/STAT3 pathway. Cell Mol Immunol 14: 127-142, 2017. 